\title{
TINGKAT KEBUGARAN JASMANI MAHASISWA KEPERAWATAN UNTAN \\ Oleh
}

\section{Edi Purnomo', Y. Touvan Juni Samodra ${ }^{2}$, Novi Yanti ${ }^{3}$ Prodi kepelatihan FKIP UNTAN 2016}

\begin{abstract}
Abstrak : Latar belakang penelitian ini didasarkan pada review kajian penelitian kebugaran disimpulka bahwa ada kecenderungan semakin orang dewasa semakin malas bergerak sehingga tidak bugar. Bukti penelitian menunjukkan hal tersebut. Sampel penelitan 25 mahasiswa keperawatan UNTAN 10 putra dan 15 putri. Di sisi lain pada akhirnya pekerjaan yang dilakukan membutuhkan tingkat kebugaran yang tinggi karena harus melawan kelelahan dan bersinggungan dengan penyakit.

Data diperoleh dengan cara dengan teknik tes dan pengukuran. Tes Kesegaran Jasmani yang Berhubungan Dengan Kesehatan, Tes Daya Tahan Jantung Paru, Tes kekuatan Otot Isometrik, Tes kekuatan Isotonik, Bent Knee Sit up (Lutut ditekuk), Push-Up, Angkat Badan Atas (Extention), Tes Duduk dan Jangkau. Data yang telah terkumpul kemudian dianalisis deskriptif statistic sederhana dalam bentuk persentase. Hasil penelitian menunjukkan bahwa tingkat kebugaran mahasiswa keperawatan UNTAN masih rendah. Sehingga direkomendasikan diadakan program untuk meningkatkan kebugaran.
\end{abstract}

Kata kunci: kebugaran jasmani

Abstrak : This research based on research reviews about fitness, based
on review research found that were as peoples mature will less inactivity
and effected on level of fitness. Samples are 25 students of nurse
UNTAN UNIVERSITY, 10 boys and 15 girl. The reasons chosen cause
they are directly contact with people ill and will be height risk if their
level of fitness are not height enough
Data collection used fitness test and measurements: endurance test,
strength isotonic test, strength isometric test, Bent Knee Sit up, Push-Up,
body Extention test. Data were collected analyzed by statistic descriptive.
Data analyzed result that fitness level of nurse student UNTAN are still

${ }^{1}$ Edi Purnomo, (dosen Jurusan Ilmu Keolahragaan FKIP UNTAN)

${ }^{2}$ Touvan Juni Samodra (dosen Jurusan Ilmu Keolahragaan FKIP UNTAN)

${ }^{3}$ Novi Yanti (dosen Jurusan Ilmu Keolahragaan FKIP UNTAN) 
bellow. The recommendation of this research is needed fitness program for students to improve the fitness level.

Key word: level fitness

\section{Pendahuluan}

Berikut disajikan bukti bukti penelitian kaitannya antara keterampilan gerak, kebugaran jasmani dalam kaitannya dengan pertumbuhan dan perkembangan anak. Tidak terkecuali ketika anak berkembangan menjadi remaja, dan akhirnya dewasa. Secara garis besar, ketika anak kurang menguasai gerak maka akan cenderung hipokenetik, anak yang hipokenetik maka akan kurang bugar, dan anak yang kurang bugar cenderung lemah dan rentan terhadap penyakit dan kurang baik kinerja akademik ataupun bergaul.

Penelitian yang dilakukan oleh Sherman, Nestor (2002) dengan judul Attitudes of preservice physical education majors regarding movement education. Menyimpulkan bahwa Sikap dan kepercayaan yang dianut oleh calon mahasiswa jurusan pendidikan jasmani terhadap pendidikan gerak sangat dipengaruhi oleh pengalaman yang dilakukan sebelumnya. Subjek penelitian ini 152 terbagi dua kelompok eksperimental (pria dan wanita) dan kelompok kontrol (dua pria dan wanita). 76 peserta 16 perempuan dan 60 lakilaki. Subjek dalam kelompok kontrol 24 perempuan dan 52 laki-laki. Survei terdiri dari sembilan pertanyaan tentang demografi dan 30 pernyataan tentang sikap. Hasil penelitian menunjukkan pengalaman gerak menghasilkan sikap positif. Berkenaan dengan demografi, penulis menyimpulkan bahwa "temuan ini mungkin menunjukkan perbedaan sehubungan dengan sosialisasi sebelumnya, pengalaman hidup, dan kesesuaian yang dirasakan dari partisipasi dalam kaitannya dengan identifikasi gender, sehingga putri lebih terlibat dalam gerak tari-tarian.

Aktivitas olahraga disusun untuk meningkatkan fungsi jantung-paru, kekuatan, kelenturan, daya tahan (unsur biomotor). Pada model ini setiap aktivitas ditujukan untuk peningkatan fitness yang bertujuan memberi bekal hidup aktif yang sehat, belajar seumur hidup dan kualitas hidup. Jason Bocarro, Michael A. Kanters, Jonathan Casper, and Scott Forrester (2008) penelitian berjudul School Physical Education, Extracurricular Sports and Lifelong Active Living. Artikel ditulis bertujuan untuk mendukung ekstrakurikuler sekolah untuk melihat dampak positif langsung dan jangka panjang, perilaku hidup sehat dan obesitas pada anak. Banyak kritik yang ditujukan terhadap perkembangan obesitas anak di Amerika, hasil dari pembahasan disimpulkan bahwa kegiatan intramural di sekolah dapat membantu siswa belajar keterampilan agar anak dapat berpartisipasi dalam olahraga yang memfasilitasi agar anak hidup aktif seumur hidup. 
Min-hua Chung (2004) Investigation of Fitness Education Model's Implementation Effects. Tujuan utama dari penelitian ini adalah untuk mengetahui implementasi "fitnes education model" dalam seting pengajaran pendidikan jasmani. Khsususnya penelitian ini terfokus pada budaya kebiasaan olahraga di masa depan dan kesulitan dalam penerapan merancang program kebugaran yang dirancang dan dilaksanakan sendiri. Guru pendidikan jasmani dengan pengalaman 7 tahun dengan 64 siswa (52 putri dan 12 putra). Program dilaksanakan selama 19 minggu. Pertemuan siswa 1 kali perminggu 90 menit. Metode pengajaran dengan ceramah, alat peraga, tes kebugaran kemontrasi dan latihan, siswa mendesain dan melaksanakan program kebugarannya, secara kelompok ataupun mandiri. Tes kebugaran dan angket diberikan setelah 2 minggu dan minggu terakhir semester. Hasil menunjukkan bahwa daya tahan, kekuatan dan daya tahan otot perut, kelenturan meningkat secara signifikan; sebagian siswa $(76.6 \%)$ yang masuk dalam program ini membantu dalam kebiasaan untuk latihan; program yang didesain mandiri memiliki empat kesulitan: mengontrol intensitas, pemilihan model latihan, kontrol pengaturan jadual kegiatan; dan program kebugaran mandiri memiliki tiga kesulitan umum: malas, tidak dapat mengikuti jadual, masalah cuaca.

Martine Meyer and Pascale Duché melakukan penelitian dengan judul Effect of a 6-month school-based physical activity program on body composition and physical fitness in lean and obese schoolchildren. Penelitian ini bertujuan untuk menilai efek dari program 6 bulan aktivitas fisik terhadap komposisi tubuh dan kebugaran fisik anak sekolah dasar. 457 anak berusia 6 10 tahun, 229 anak diadakan eksprerimen 228 anak kelompok kontrol. Diukur tinggi dan berat badan serta ditentukan tingkat obesitas anak di bagian tempat dengan skinfold. Tes aerobik mengunakan lari bolak-balik $20 \mathrm{~m}$ dan tes aerob menggunakan tes kebugaran yang pernah di teskan. Hasil penelitian menyatakan bahwa aerobik dan anaerob meningkat secara sifnifikan, tetapi tidak berpengaruh terhadap antopomerti tubuh. Dianjurkan agar dua kali aktivitas fisik perminggu di luar jam pendidikan jasmani dapat secara efektif mencegah anak dari obesitas

Clare Hume, Anthony Okely, Sarah Bagley, Amanda Telford (2008). Does weight status influence associations between children's fundamenta Imovement skills and physical activity? Penelitian ini berusaha untuk mengetahui pengaruh berat badan anak berhubungan dengan keterampilan motorik dasar anak dan aktivitas fisik. 248 anak usis 9-12 tahun berpartisipasi dalam penelitian ini. Diberikan 3 tes keterampilan manipulasi dan dua lokomotor. Ditentukan indek masa tubuh. Kemudian dikorelasikan antara aktivitas fisik dan keterampilan motorik dasar antara putra dan putri. Tidak ada interaksi yang signifikan antara keterampilan motorik dasar, aktivitas fisik 
dan status berat badan. Penelitian lebih lanjut disarankan untuk memperbanyak jenis keterampilan dan aktivitas-aktivitas untuk lebih mencirikan keterhubungan dan menginformasikan kecakapan penguasaan keterampilan gerak.

Berdasarkan penelitian yang ada dapat diambil kesimpulan beberapa hal. Bahwa kebugaran dapat tercapai jika melakukan aktivitas jasmani, baik itu hidup aktif ataupun mengikuti kegiatan olahraga. Kedua kegiatan olahraga sebaiknya dilakukan tiga (3) kali dalam seminggu dengan dosis aerobic. Fakta penelitian menunjukkan bahwa ketika anak kurang dalam kemampuan gerak dasar maka akan mengalami kesulitan dalam belajar gerak pada periode berikutnya. Hal ini akan mengakibatkan anak kurang berpartisipasi dalam aktivitas jasmani ketika telah dewasa yang akan berakibat pada tingkat kebugaran di masa siklus kehidupan. Ketiga ketika siswa kurang gerak akan berpengaruh terhadap rasa percaya diri untuk mengikuti aktivitas jasmani terlebih kegiatan olahraga, hal ini berkaitan dengan tingkat penguasaan keterampilan serta mempengaruhi secara psikologis.

Berdasarkan review beberapa penelitian berikutnya penelitian yang dilakukan oleh (Connor-Kuntz \& Dummer, 1996; Goodway \& Branta, 2003; Hamilton et al., 1999; Valentini \& Rudisill, 2004b) ..." some populations of children do not receive appropriate kinds of movement experiences" dikatakan bahwa anak tidak memperoleh pengalaman gerak dengan semestinya. Menurut peneliti ada beberapa hal yang terjadi sehingga kebutuhan akan keterampilan gerak kurang terpenuhi dan belum sebagaimana mestinya. Program gerak yang terjadi dan kemungkinan juga terjadi di Indonesia adalah; (a) tidak ada perencanaan (b) tidak ada tujuan dan sasaran yang jelas (c) waktu yang tidak mencukupi untuk latihan keterampilan gerak, (d) keterbatasan model dan contoh dan (e) peralatan yang tidak cocok (Goodway \& Branta; Rink, 2006 dalam Leah E Robinson, Jacqueline D Goodway (2009)).

Jadwiga Szymura, Joanna Gradek, Marcin Maciejczyk, Magdalena Więcek, JerzyCempla (2011) melakukan penelitian dengan judul The anaerobic capacity in obese children. Banyak artikel menunjukkan bahwa kapasitas aerobik anak obesitas putra dan putri rendah, tetapi bukti informasi anaerobik terbatas. Penelitian ini bertujuan untuk memperkirakan keterlibatan gender dalam tingkat obesitas dan tingkat kapasitas anerobik anak usis 9-10 tahun. 22 anak putra kelebihan lemak dan 20 putri berpartisipasi dalam penelitian ini dan juga 20 putra dan putri yang tidak obes. Diukur tingkat maksimal anaerob anak dengan cycloergometer yang di seting meningkat. Hasilnya menunjukkan jumlah nilai total kapasitas anaerobik 15\% lebih tinggi kelompok anak yang tidak mengalami obes. Nilai indek masa tubuh anak yang tidak obes lebih rendah. Waktu untuk pencapai kapasitas maksimal anak obes 
lebih pendek tetapi irama mengayuh kurang lebih sama. Nilai secara keseluruhan kapasitas anaerobik maksimal antara putra dan putri secara signifikan putra lebih tinggi dibandingkan putri . Kesimpulannya berdasarkan hasil ini kelompok yang tingkat anaerobiknya rendah adalah anak yang mengalami obes.

Berbagai hal di atas dalam pengamatan peneliti banyak terjadi di sekolah bukan hanya dari Sekolah dasar sampai sekolah menengah umum, hal ini semakin parah ketika menginjak usia mahasiswa. Diketahui bersama bahwa perguruan tinggi kurang menyediakan kegiatan yang cukup bagi mahasiswa untuk beraktivitas menggunakan jasmani dalam intensitas cukup untuk mencapai kebugaran. Kuliah di perguruan tinggi identik dengan tugas membaca tumpukan buku teori serta penyusunan laporan perkuliahan hasil dari kuliah praktikum.

Darla M (2007) meneliti kaitan antara prestasi akademik dengan tingkat kebugaran jasmani. Hasil penelitian menunjukkan bahwa kebugaran jasmani berkorelasi dengan beberapa subyek pelajaran diantaranya pelajaran matematika dan pelajaran membaca pada kelas 3 dan 5 sekolah dasar. Penelitian kedua menunjukkan hal yang sama menyatakan bahwa siswa dengan kebiasaan aktivitas jasmani yang tinggi memiliki tingkat capaian akademik yang lebih baik penelitian ini dilakukan terhadap 214 siswa kelas 6 (DAWN PODULKA COE, 2006).

Berbagai kajian penelitian yang telah dipaparkan memberikan bukti argumentasi yang cukup bahwa kebugaran jasmani sangat penting. Kebugaran ini banyak didukung oleh faktor faktor yang lain, diantaranya pengalaman gerak, pengalaman olahraga, pengalaman pendidikan jasmani, ketersedian organsiasi olahraga, ketersediaan sarana prasarana, kekreatifan instruktur dalam memberikan pengalaman aktivitas jasmani. Berbagai faktor menjadi hal penting sehingga siswa yang pada akhirnya menjadi mahasiswa untuk selalu berparatisipasi dalam aktivitas jasmani untuk menjaga kebugaran. Serangkaian bukti penelitian yang menerangkan runtutan bagaimana kebugaran jasmani diperoleh telah dipaparkan. Yang menjadi permasalahan adalah apakah di usia mahasiswa kebugaran jasmani ini masih menjadi hal yang diperhatikan.

\section{Identifikasi Masalah}

Mahasiswa merupakan masa belajar pada puncak pendidikan tertinggi. Secara teoritis orang yang bugar akan lebih mampu menerima beban belajar yang lebih berat. Mahasiswa yang kurang bugar akan mengalami kesulitan dalam mengatasi beban kuliah. Kelelahan akan terjadi dan ketika kelelahan menumpuk maka akan mempengaruhi kenerja akademik. 
Wadah untuk melakukan aktivitas jasmani yang mengarah pada kebugaran di perguruan tinggi relative kurang diperhatikan dan kurang serius dari mahasiswa. Waktu yang dimiliki mahasiswa telah dihabiskan untuk belajar dan menyusun laporan-laporan yang dibebankan kemada mahasiwa.

Khususnya mahasiswa keperawatan UNTAN jelas memiliki jumlah jam yang sedikit untuk melakukan aktivitas jasmani dengan ketatnya jadual praktek dan teori yang harus dijalani. Di sisi lain pada akhirnya pekerjaan yang dilakukan membutuhkan tingkat kebugaran yang tinggi karena harus melawan kelelahan dan bersinggungan dengan penyakit. Sehingga kebugaran fisik sangat diperlukan untuk menunjang belajar, praktek serta menulis laporan selama kuliah.

\section{Pertanyaan penelitian}

Berdasarkan pada pembatasan masalah maka rumusan masalah secara umum adalah, bagaimana tingkat kebugaran mahasiswa keperawatan UNTAN?

\section{Kebugaran Jasmani}

Menurut Menurut Judith Rink dan Mochamad Sajoto, kebugaran Jasmani adalah kemampuan seseorang menyelesaikan tugas sehari-hari dengan tanpa mengalami kelelahan berarti, dengan pengeluaran energi yang cukup besar, guna memenuhi kebutuhan geraknya dan menikmati waktu luang serta untuk memenuhi keperluan darurat bila sewaktu-waktu diperlukan. Sedangkan Menurut Djoko Pekik, Kebugaran jasmani merupakan kemampuan seseorang melakukan kerja sehari-hari secara efisien tanpa timbul kelelahan yang berlebihan sehingga masih menikmati waktu luangnya. Menurut Kockey dalam Sumarjo (2002: 43) kebugaran jasmani adalah kemampuan untuk menyelesaikan tugas sehari-hari dengan mudah, tanpa kelelahan yang berarti dan masih dapat menikmati waktu senggangnya serta dalam keadaan darurat masih mampu melakukan pekerjaan yang tak terduga. Menurut Sadoso Sumosardjuno (1998: 19) kebugaran jasmani adalah, kemampuan seseorang untuk menunaikan tugasnya sehari-hari dengan gampang, tanpa merasa lelah yang berlebihan, dan masih mempunyai sisa atau cadangan tenaga untuk menikmati waktu senggangnya dan keperluan-keperluan yang mendadak. Dapat pula ditambahkan, kebugaran jasmani merupakan kemampuan untuk menunaikan tugas dengan baik walaupun dalam keadaan sukar, dimana orang yang kesegarannya kurang, tidak akan dapat melakukannya. Selain itu menurut Muhajir (2004:2) kebugaran jasmani adalah kesanggupan dan kemampuan tubuh melakukan penyesuaian (adaptasi) terhadap pembebasan fisik yang diberikan kepadanya (dari kerja yang dilakukan sehari-hari) tanpa menimbulkan kelelahan yang berlebihan. 
Lausanne Schweiz (1999) melakukan penelitian berjudul Sports activity, physical activity and fitness of 9- to 19-year-old teenagers in the canton of Vaud (Switzerland). Penelitian ini dilatar belakangi sedikitnya penelitian efek aktivitas fisik terhadap kebugaran pada anak. Penelitian dilakukan dengan survey 1778 anak putri dan 1762 putra dengan 7 test batre untuk mengukur kebugaran. Dilakukan juga tes antopometri, angket aktivitas fisik dan gaya hidup. Hasil penelitian menunjukkan sebagai responden secara teratur berolahraga tetapi putra lebih baik dibandingan dengan putri $75 \%$ dan putri 56\% melakukan aktivitas sampai bekeringat. Berdasarkan kelas, 56\% sampai $74 \%$ putri dan 62 sampai $88 \%$ putra berpartisipasi dalam klub olahraga, berdasarkan tes kebugaran dinyatakan bahwa putri lebih lentur dibandingan dengan putra sementara kekuatan dan daya tahan putra lebih besar setelah usia lebih dari 15 tahun. Perhitungan BMI dan VO2max anak masuk dalam norma yang dipublikasikan dalam literatur internasional. Kesimpulannya program untuk meningkatkan aktivitas fisik harus secara khusus sesuai dengan perbedaan gender dan dikhususkan untuk anak yang berumur lebih dari 15 tahun. Untuk memonitor kebugaran dan aktivitas fisik dapat mengunakan tes betre dan angket.

\section{Metode penelitian}

Penelitian ini merupakan penelitian deskriptif untuk mengetahui kebugaran Khususnya mahasiswa keperawatan UNTAN. Sampel penelitan ini adalah mahasiswa keperawatan UNTAN berjumlah 25 mahasiswa. Data diperoleh dengan cara dengan teknik tes dan pengukuran.

Tes Kesegaran Jasmani yang Berhubungan Dengan Kesehatan, Tes Daya Tahan Jantung Paru, Tes kekuatan Otot Isometrik, Tes kekuatan Isotonik, Bent Knee Sit up (Lutut ditekuk), Push-Up, Angkat Badan Atas (Extention), Tes Duduk dan Jangkau.

Data yang telah terkumpul kemudian dianalisis deskriptif statistic sederhana dalam bentuk persentase.

\section{Deskripsi Hasil Penelitian}

Subjek penelitian adalah mahasiswa keperawatan Universitas Tanjungpura Pontianak yang berjumlah 25 mahasiswa, yang terdiri dari 15 mahasiswa perempuan dan 10 mahasiswa laki-laki. Subjek penelitian yang terdiri dari 25 mahasiswa di tes atau diukur kebugaran jasmani.

Hasil data terhadap 6 item tes tersebut kemudian disusun kembali berdasarkan klasifikasi yang sesuai kriteria masing-masing tes dengan mengunakan acuan dari Vivian $\mathrm{H}$. Hayward. Advances fitness assessment and 
exercise prescription. $3^{\text {rd }}$ Ed. Human Kinetic. Mexico. 1998. Sehingga dapat dideskripsikan sebagai berikut:

\begin{tabular}{|c|c|c|c|c|c|c|c|}
\hline $\mathrm{N}$ & tes & $\begin{array}{c}\text { Respon } \\
\text { den }\end{array}$ & $\begin{array}{c}\text { Baik } \\
\text { sekali }\end{array}$ & Baik & Cukup & Kurang & $\begin{array}{r}\text { Kurang } \\
\text { sekali }\end{array}$ \\
\hline \multirow[t]{2}{*}{1} & \multirow{2}{*}{$\begin{array}{l}\text { Tes } \\
\text { menggeng } \\
\text { gam (kg) }\end{array}$} & Putra & & & $1(10 \%)$, & $3(30 \%)$ & $6(60 \%)$ \\
\hline & & Putri & & & $(53.33 \%)$ & $7(46.67 \%)$ & \\
\hline \multirow[t]{2}{*}{2} & \multirow{2}{*}{$\begin{array}{l}\text { Sit-Up } 60 \\
\text { detik }\end{array}$} & Putra & & & & $1(10 \%)$ & $9(90 \%)$ \\
\hline & & Putri & & & & $3(20 \%)$, & $12(80 \%)$ \\
\hline \multirow[t]{2}{*}{3} & \multirow{2}{*}{$\begin{array}{l}\text { Push-Up } \\
60 \text { detik }\end{array}$} & Putra & & & & $2(20 \%)$ & $8(80 \%)$ \\
\hline & & Putri & & $2(13.33 \%)$ & $3(20 \%)$ & $7(46.67 \%)$ & $3(20$ \\
\hline \multirow[t]{2}{*}{4} & \multirow{2}{*}{$\begin{array}{l}\text { Trunk } \\
\text { extension }\end{array}$} & Putra & $2(20 \%)$ & $3(30 \%)$ & $5(50 \%)$ & & \\
\hline & & Putri & & $4(26.67 \%)$ & $4(26.67 \%)$ & $6(40 \%$ & $1(6.67 \%)$ \\
\hline \multirow[t]{2}{*}{5} & \multirow{2}{*}{$\begin{array}{l}\text { Sit and } \\
\text { reach }\end{array}$} & Putra & & $3(30 \%)$ & $4(40 \%)$ & $3(30 \%)$ & \\
\hline & & Putri & & $3(20 \%)$, & $5(33.33 \%)$ & $7(46.67 \%)$ & \\
\hline \multirow[t]{2}{*}{6} & \multirow{2}{*}{$\begin{array}{l}\text { Tes multi } \\
\text { tahap }\end{array}$} & Putra & & & $2(20 \%$ & $8(80 \%)$ & \\
\hline & & Putri & & & $1(6.67 \%)$ & $12(80 \%)$ & $2(13.3 \%)$ \\
\hline
\end{tabular}

Berdasarkan tabel diatas dapat dilihat bahwa secara garis besar status kebugaran mahasiswa baik putra dan putri hampir pada level yang rendah. Hal ini dapat dilihat bahwa hanya ada $2(20 \%)$ yang masuk pada kategori baik sekali dari 25 mahasiswa pada satu item tes yaitu kelenturan togok sedangkan bagian utama pendukung kebugaran yaitu tes multi tahap tidak satu pun baik apalagi baik sekali.

\section{Pembahasan}

Kesegaran jasmani dapat dibagi menjadi dua aspek kebugaran jasmani yaitu kebugaran jasmani yang berhubungan dengan kesehatan (health related fitness) dan kebugaran yang berhubungan dengan keterampilan (skill related fitness). Kebugaran jamani yang berhubungan dengan kesehatan meliputi; a) daya tahan paru jantung (kardiorespisari), b) kekuatan otot, c) daya tahan otot, d) fleksibilitas dan komposisi tubuh(Widiastuti, 2011:14).

\section{Kekuatan Otot.}

Kebugaran otot adalah kemampuan untuk melaksanakan pekerjaan terhadap tahanan atau beban. Kekuatan maksimal tergantung pada beberapa faktor (misalnya, ukuran dan jumlah otot yang terlibat, proporsi serat otot dalam gerakan, koordinasi kelompok otot, dll) tidak ada tes tunggal untuk mengukur kekuatan otot. Komponen kebugaran otot yang berhubungan dengan kesehatan utama adalah kekuatan maksimal (isometrik dan dinamis), kekuatan 
power, kekuatan daya tahan dan kekuatan isokinetic (FB Ortega,JR Ruiz,MJ Castillo \& M Sjostro, 2007:2). Tes yang digunakan pada penelitian ini adalah tes kekuatan menggenggam, tes sit up dan push up. Hasil ketiga item tes kekuatan adalah sebagai berikut; hasil tes kekuatan menggenggam menunjukan $36 \%$ termasuk dalam kategori baik dan $64 \%$ termasuk dalam kategori kurang/ rendah; hasil tes sit-up 100\% mahasiswa termasuk dalam kategori kurang; dan terakhir tes push up terdapat $28 \%$ mahasiswa yang termasuk dalam kategori baik dan $78 \%$ mahasiswa masuk dalam kategori rendah. Berdasarkan hasil beberapa tes tersebut dapat disimpulkan bahwa kemampuan kekuatan otot mahasiswa keperawatan rendah.

Kekuatan otot merupakan hal yang sangat penting bagi setiap individu. Kekuatan adalah kemampuan neurmuekuler menghasilkan kekuatan untuk mengatasi tahanan atau beban dari luar (Bompa, 2009: 261). Sukadiyanto (2010:131) kekuatan adalah kemampuan otot atau sekelompok otot untuk mengatasi beban atau tahanan. Widiastuti (2011:76)kekuatan otot adalah kemampuan otot atau sekelompok otot untuk melakukan kontraksi secara maksimal untuk melawan tahanan atau beban. Kekuatan otot sangat diperlukan setiap individu, tanpa terkecuali mahasiwa keperawatan. Kekuatan otot berperan penting dalam semua aktivitas yang dilakukan oleh individu. Menurut Widiastuti (2011: 76) sebagai daya penggerak setiap aktivitas fisik, kekuatan otot merupakan komponen penting. Memiliki kekuatan otot yang baik memungkinkan individu terhidar dari cidera, selain itu juga membantu kecepatan individu dalam melakukan suatu gerakan, dan stabilitas sendi-sendi samakin kuat.

\section{Kelenturan/ fleksibilitas.}

Hasil tes kelenturan menunjukan bahwa kelenturan mahasiswa keperawatan memliki kelenturan yang baik, hal ini ditunjukan dengan hasil kedua tes kelenturan yang dilakukan mahasiswa. Mahasiswa yang memiliki kelenturan trunk extension dalam kategori baik sebanyak 96\% dan mahasiswa yang memiliki kelenturan trunk extension dalam kategori kurang sebanyak $4 \%$. Hasil tes sit and reach mahasiswa keperawatan menunjukan $100 \%$ masuk dalam kategori baik. Berdasarkan hasil penelitian tersebut dapat disimpulkan bahwa mahasiswa keperawatan memiliki kelenturan yang baik.

Kelenturan mengandung makna kualitas gerak pada persendian yang didukung oleh kulaitas otot, tendon dan ligament (Djoko Pekik Irianto dkk, 2009:21). Kfleksibilitas mengandung pengertian luas gerak satu persendian atau beberapa persendian (sukadiyanto, 2010: 207). Sebagai komponen kebugaran, fleksibilitas mencakup semua elemen yang berkontribusi terhadap sistem muskuloskeletal keseluruhan, seperti otot itu sendiri, ligamen, tendon, 
struktur tulang, jalur saraf, sendi dan bahkan kulit (Gordon, D. (2009: 177). Menurut Sukadiyanto (2010: 206) ada beberapa keuntungan bagi individu yeng memiliki kualitas fleksibilitas yang baik yaitu: 1) akan memudahkan individu dalam menampilkanberbagai kemampuan gerak dan keterampilan, 2) menghindarkan individu dari kemungkinan terjadinya cidera pada saat melakukan aktivitas, 3) memungkinkan individu untuk dapat melakukan aktivitas yang ekstrim, 4) memperlancar peredaran darah sehingga sampai keserabut otot

\section{Daya tahan kasdiorespirasi.}

Hasil tes multi-tahap menunjukan bahwa vo2max mahasiswa keperawatan sangat rendah sekali dari 25 mahasiswa hanya $12 \%$ mahasiswa yang memiliki katergori cukup dan $88 \%$ masuk pada kategori rendah atau kurang.

Kebugaran kardiorespirasi, juga disebut kebugaran kardiovaskular adalah kapasitas keseluruhan dari jantung dan sistem pernapasan dan kemampuan untuk melaksanakan latihan berat yang berkepanjangan. WHO menganggap bahwa konsumsi oksigen maxsimal (vo2max) yang dicapai setelah latihan merupakan indicator terbaik untuk menentukan kebugaran kardiorespirasi (FB Ortega,JR Ruiz,MJ Castillo \& M Sjostro, 2007:2).

Daya tahan jantung dan paru adalah kesanggupan system jantung, paru-paru dan pembuluh darah untuk berfungsi secara optimal saat melakukan aktivitas sehari-hari, dalam waktu yang cukup lama tanpa mengalami kelelahan yang berarti. Daya tahan paru jantung sangat penting untuk menunjang kerja otot, yaitu dengan cara mengambil oksigen dan menyalurkannya ke otot yang aktif (Widiastuti, 2011:14). Pengertian ketahanan adalah kemampuan organ tubuh untuk melawan kelelahan selama berlangsungnya aktivitas kerja. Factor yang berpengaruh terhadap ketahanan adalah kemampuan maksimal dalam memenuhi konsumsi oksigen yang ditandai dengan VO2max. Komponen biomotor ketahanan pada umumnya digunakan sebagai salah satu tolak ukur untuk mengetahui tingkat kebugaran jasmani (physical fitness) (Sukadiyanto, 2010: 88) kebugaran jasmani adalah suatu keadaan kemampuan organ tubuh yang dapat memilihara keseimbangan ketersedianya energy sebelum, selama dan sesudah aktivitas kerja berlangsung. Kemampuan vo2max mahasiswa keperawatan masuk dalam ketegori kurang ini dapat disimpulkan bahwa tingkat kebugaran mahasiswa keperawatan rendah, daya tahan yang rendah akan mengakibatkan seseorang akan mudah mengalami kelelahan. Hal ini sangat disayangkan mengingat mahasiswa keperawatan penuh dengan aktivitas kuliah yang padat dan ditambah jam praktek tambahan yaitu piket malam di salah satu rumah sakit. Ditambah mahasiwa keperawatan bersinggungan 
langsung dengan berbagai macam penyakit, sehingga rentan terserang penyakit.

\section{Simpulan dan Saran}

Berdasarkan pada hasil peneltian dan beberapa butir pembahasan diatas dapat disimpulkan beberapa hal:

1. Dilihat dari sisi kebugaran kardiorespirasi mahasiswa sebagai subyek penelitian masih sangat rendah

2. Dilihat dari sisi kekuatan secara keseluruhan juga masih rendah

3. Dilihat dari sisi kelenturan masuk dalam kategori baik

4. Dilihat dari tes ketahanan sit up dan push up dalam kategori kurang Berdasarkan beberapa indikator tersebut dapat dipahami bahwa ternyata tingkat kualitas fisik mahasiswa subyek penelitian masih kurang

Berdasarkan data, analisis dan pembahasan serta kesimpulan dapat disarankan beberapa hal:

1. Perlu adanya upaya peningkatan kualitas jasmani kaitannya dengan kebugaran, agar difasilitasi untuk melakukan aktivittas jasmani yang mendukung terhadap kebugaran

2. Keterkaitan dengan daya tahan otot lokal masih perlu untuk ditingkatkan dengan program aktivitas jasmani agar mendukung kualitas mahasiswa

\section{DaftarPustaka}

Adisaputra, Iskandar.Z, Primana, Dadang.A, Asim, dkk. (1999). Panduan Teknis Tes dan Latihan Kesegaran Jasmani Pada Seminar dan Widiakarya Nasional Olahraga dan Kesegaran Jasmani, Hotel Sahid Jaya, 6-7 September 1999. Pusat Pengkajian dan Pengembangan Iptek Olahraga Kantor Kementrian Negara Pemuda dan Olahraga

Anonymous. (Mar 2005). The Impact of Intervention of a Motor Skills Program on Preschool Children's Fundamental Motor Skills and Cognition of Movement Concept. http://proquest.umi.com/pqdweb? index $=34 \&$ did $=804360511 \&$ SrchMode $=1 \&$ sid $=1 \&$ Fmt $=3 \&$ VInst $=$ PRO D\&VType $=\mathrm{PQD} \& \mathrm{RQT}=309 \& \mathrm{VName}=\mathrm{PQD} \& \mathrm{TS}=1307938331 \&$ clientI $\mathrm{d}=83698$

Anonymous.USA Today. (Sep 2010)..BasicMotor SkillsLacking in Preschoolers.http://proquest.umi.com/pqdweb?index $=1 \&$ did=21404298 $81 \&$ SrchMode $=1 \&$ sid $=1 \&$ Fmt $=3 \&$ VInst $=$ PROD $\& V T y p e=P Q D \& R Q T=$ 309\&VName $=$ PQD \&TS $=1307937322 \&$ clientId $=83698$

Anthony D Okely, Michael L Booth, Tien Chey.(2004) Relationships Between Body Composition and Fundamental Movement Skills Among Children and Adolescents. di download tangal 4 Maret 2012. Tersedia 
$d i$ :http://proquest.umi.com/pqdweb?index $=35 \&$ did=699308211\&SrchM ode $=1 \&$ sid $=1 \&$ Fmt $=4 \&$ VInst $=$ PROD $\& V T y p e=P Q D \& R Q T=309 \& V N a$ me $=$ PQD \&TS $=1307938331 \&$ clientId $=83698$

Bompa. T.O \& Haff. G.G (2009). Periodetizion: theory and methodology of training $\left(5^{t h} \mathrm{ed}\right)$. USA: Human Kinetics.

Clare Hume, Anthony Okely, Sarah Bagley, Amanda Telford. (2008). Does Weight Status Influence Associations Between Children's Fundamental Movement Skills and Physical Activity? di download tangal 4 Maret 2012. Tersedia di: http://proquest.umi.com /pqdweb?index $=17 \& \mathrm{did}=1510078631 \&$ SrchMode $=1 \& \mathrm{sid}=1 \& \mathrm{Fmt}=3 \&$ VInst $=$ PROD $\&$ VType $=\mathrm{PQD} \& \mathrm{RQT}=309 \& \mathrm{VName}=\mathrm{PQD} \& \mathrm{TS}=1307937807 \&$ clientId $=8$ 3698

Christopher $R$ Kovacs. Strategies.( Nov/Dec 2008). Measuring Motor Skill Learning-A Practical Application. http://proquest.umi.com /pqdweb?index $=12 \&$ did $=1598881341 \&$ SrchMode $=1 \&$ sid $=1 \&$ Fmt $=3 \&$ VInst=PROD\&VType $=$ PQD\&RQT $=309 \&$ VName $=P Q D \& T S=1307937$ 807\&clientId $=83698$

Clersida Garcia, Luis Garcia, Jarald Floyd, John Lawson. (Jan 2002). Improving public health through early childhood movement programs. http://proquest.umi.com/pqdweb?index=37\&did=99641401\&SrchMode $=1 \&$ sid $=3 \&$ Fmt $=4 \&$ VInst $=$ PROD $\&$ VType $=P Q D \& R Q T=309 \& V$ Name $=$ PQD\&TS $=1307679086 \&$ clientId $=83698$

David Stodden, Stephen Langendorfer, Mary Ann Roberton.(2009). The Association Between Motor Skill Competence and Physical Fitness in Young Adult .di download tangal 4 Maret 2012. Tersedia di:shttp://proquest.umi.com/pqdweb?index=12\&did=1796465301\&Srch Mode $=1 \&$ sid $=8 \&$ Fmt $=3 \&$ VInst $=$ PROD $\& V T y p e=P Q D \& R Q T=309 \& V$ Name $=$ PQD \&TS $=1310634466 \&$ clientId $=83698$

Djoko Pekik Irianto, dkk. (2009). Materi latihan kondisi fisik dasar. Jakarta: ASDEP Pengembangan Tenaga dan Pembinaan Keolahragaan.

Fatma Çelik Kayap2nar (2011). The Effect of Movement Education Program on Static

Balance Skills of Pre-School Children. World Applied Sciences Journal 12 (6): 871-876, 2011. Department of Physical Education and Sports Teaching, Faculty of Education, Mehmet Akif Ersoy University, Burdur, Turkey Fisher, abigail; Reilly, john j.; Kelly, Louise a.; Montgomery, Colette; williamson, Avril; Paton, James y.; Grant, Stan.(2005).Fundamental Movement Skills and Habitual Physical Activity in Young Children. Di download tanggal 9 februadi. Tersedia di: http://journals.lww.com/acsm- 
msse/Abstract/2005/04000/Fundamental_Movement_Skills_and_Habitu al Physical.23.aspx

FB Ortega,JR Ruiz,MJ Castillo \& M Sjostro. (2007) Physical fitness in childhood and adolescence: a powerful marker of health. internasional Journal of Obesity (2008) 32,1-11; doi: 10.1038 / sj.ijo.0803774; dipublikasikan secara online 4 Desember 2007. http://www.nature.com/ijo/journal/v32/n1/pdf/0803774a.pdf.

Gordon, D. (2009). Coaching science. Britain: Learning Matters Ltd.

Goodway, Jacqueline D; Wall, Sarah; Getchell, Nancy. Strategies 23. 2. (2009).Promoting an "Active Start" for Young Children: Developing Competent and Confident Early Movers. Di download tanggal 18 november

2011:http://search.proquest.com/docview/214554557/fulltext/1330A56E 7C718DAC979/117? accountid $=35150$

Hardy LL, King L, Farrell L, Macniven R, Howlett S.( 2010)Fundamental movement skills among Australian preschool children.Di download tanggal 9 februadi. Tersedia di: http://www .ncbi.nlm.nih.gov/pubmed/ 19850520

Ian Maddison( Spring 1998) Fundamental Motor Skills (FMS) a Victorian department of education initiative. http://proquest. umi.com/ pqdweb? index $=53 \&$ did $=37103744 \&$ SrchMode $=1 \&$ sid $=8 \& \mathrm{Fmt}=4 \& \mathrm{VIns}$ $\underline{\mathrm{t}=\mathrm{PROD} \& \mathrm{VType}=\mathrm{PQD} \& \mathrm{RQT}=309 \& \mathrm{VName}=\mathrm{PQD} \& \mathrm{TS}=1310635850 \&}$ clientId $=83698$

Jadwiga Szymura1, JoannaGradek, MarcinMaciejczyk, Magdalena Więcek, JerzyCempla.(2011) The anaerobic capacity in obese children. Original Articles / Praceoryginalne

ISSN 1232-9886..Copyright @ Cornetis, www.cornetis.pl

James b grissom.(2005). Physical fitness and academic achievement.Volume 8 Number 1 February .Journal of Exercise Physiologyonline

Jason Bocarro,1 Michael A. Kanters, 1 Jonathan Casper,1 and Scott Forrester2.(2008) School Physical Education,Extracurricular Sports,and Lifelong Active Living. Journal of Teaching in Physical Education, 2008, 27, 155-166@ Humun. Kinetics, Inc. Carolina

Jeff Hoffman. (2003). The influence of motor skill interventions on disadvantaged children.di download tangal 4 Maret 2012. Tersedia di:http://proquest.umi.com/pqdweb?index $=37 \&$ did $=454273851 \&$ SrchM ode $=1 \&$ sid $=1 \&$ Fmt $=3 \&$ VInst $=$ PROD $\& V T y p e=P Q D \& R Q T=309 \& V N a$ me $=$ PQD $\&$ TS $=1307938331 \&$ clientId $=83698$

Jeff R. Crane, PJ Naylor, Rick Bell, Buffy-Lynne Williams, and Viviene A. (2011).Off to a great start? The motor skill proficiency of children in 
Kindergarten.School of Exercise Science, Physical and Health Education; University of Victoria, BC.

Joanne Hui-Tzu Wang (2004) A Study on Gross Motor Skills of Preschool Children. Journal of research in childhood education. http://proquest.umi.com/pqdweb?index $=22 \&$ did $=730763211 \&$ SrchMod $\mathrm{e}=1 \& \mathrm{Fmt}=4 \& \mathrm{VInst}=$ ReferenceLinking $\& \mathrm{VType}=\mathrm{PQD} \& \mathrm{RQT}=309 \& \mathrm{VN}$ ame=PQD\&TS=1307939036\&clientId=83698

Joanne Hui-Tzu Wang.(2004) A Study on Gross Motor Skills of Preschool Children. di download tangal 4 Maret 2012. Tersedia di: http://proquest.umi.com/pqdweb?index=22\&did=730763211\&SrchMod $\mathrm{e}=1 \&$ Fmt $=4 \&$ VInst $=$ ReferenceLinking $\&$ VType $=P Q D \& R Q T=309 \& V N$ ame $=$ PQD $\& T S=1307939036 \&$ clientId $=83698$

Jeff Hoffman (2003) The influence of motor skill interventions on disadvantaged children. di download tangal 4 Maret 2012. Tersedia di: http://proquest.umi.com/pqdweb?index $=37 \&$ did $=454273851 \&$ SrchMod $\mathrm{e}=1 \& \mathrm{sid}=1 \& \mathrm{Fmt}=3 \& \mathrm{VInst}=\mathrm{PROD} \& \mathrm{VType}=\mathrm{PQD} \& \mathrm{RQT}=309 \& \mathrm{VName}$ $=$ PQD\&TS $=1307938331 \&$ clientId $=83698$

John T Foley, Stephen Harvey, Hae-Ja Chun, So-Yeun Kim (2008) The relationships among fundamental motor skills, health-related physical fitness, and body fatness in South Korean adolescents with mental retardation. Di download tanggal 9 februadi. Tersedia di: http://www.mendeley.com/research/relationships-among-fundamentalmotor-skills-healthrelated-physical-fitness-body-fatness-south-koreanadolescents-mental-retardation/

Kathleen Williams. (Aug 2004)What's Motor Development Got to Do with Physical Education?

http://proquest.umi.com/pqdweb?index $=27 \&$ did $=678652611 \&$ SrchMode $=1 \&$ sid $=3 \&$ Fmt $=4 \&$ VInst $=$ PROD $\& V T y p e=P Q D \& R Q T=309 \& V N a m e=P Q$ D\&TS $=1307678894 \&$ clientId $=83698$

Keith J Hyatt, Jennifer Stephenson, Mark Carter (2009).A Review of Three Controversial Educational Practices: Perceptual Motor Programs, Sensory Integration, and Tinted Lenses Education \& Treatment of Children. Pittsburgh: tersedia di: http://proquest.umi.com /pqdweb? index $=2 \&$ did $=1702166081 \&$ SrchMode $=1 \&$ sid $=1 \&$ Fmt $=3 \&$ VI nst $=$ PROD $\&$ VType $=$ PQD $\& R Q T=309 \& V N a m e=P Q D \& T S=130182047$ $5 \&$ clientId $=83698$

Lausanne Schweiz . Peer reviewed article (1999). Sports activity, physical activityand fitness of 9- to 19-year-old teenagers in the canton of Vaud (Switzerland). a Institut universitaire de médecine sociale 
Leah E Robinson. (2011). Effect of a Mastery Climate Motor Program on Object Control Skills and Perceived Physical Competence in Preschoolers. di download tangal 4 Maret 2012. Tersedia di: http://proquest.umi.com/pqdweb?index $=1 \&$ did $=2384154581 \&$ SrchMod $\mathrm{e}=1 \&$ sid=4\&Fmt=3\&VInst=PROD $\&$ VType $=$ PQD $\&$ RQT $=309 \&$ VName $=\mathrm{PQD} \& \mathrm{TS}=1310624023 \&$ clientId $=83698$

Leah E Robinson, Jacqueline D Goodway (Sep 2009). Instructional Climates in Preschool Children Who Are At-Risk. Part I: Object-Control Skill Developmenthttp://proquest.umi.com/pqdweb?index $=1 \&$ did $=18567073$ 91\&SrchMode $=1 \&$ sid $=2 \& \mathrm{Fmt}=3 \& \mathrm{VInst}=\mathrm{PROD} \& \mathrm{VType}=\mathrm{PQD} \& \mathrm{RQT}=$ $309 \&$ VName $=$ PQD \&TS $=1307677726 \&$ clientId $=83698$. Di downloadtanggal 10 juni 2011

Lisa M Barnett, Eric van Beurden, Philip J Morgan, Lyndon O Brooks, John $R$ Beard. (Jun 2010). Gender Differences in Motor Skill Proficiency From Childhood to Adolescence: A Longitudinal Study. http://proquest.umi.com/pqdweb?index $=3 \&$ did=2042719361\&SrchMod $\mathrm{e}=1 \& \mathrm{Fmt}=3 \& \mathrm{VInst}=$ ReferenceLinking $\& \mathrm{VType}=\mathrm{PQD} \& \mathrm{RQT}=309 \& \mathrm{VN}$ ame $=$ PQD $\&$ TS $=1307939081 \&$ clientId $=83698$

Linda. M Larson (1994) Preschool physical education: Expanding the role of teacher. Di download tanggal 18 november 2011.

http://search.proquest.com/docview/215771457/fulltext/1330A56E7C71 8DAC979/96? accountid $=35150$

Min-hua Chung. (2004). Investigation of Fitness Education Model's Implementation Effects .Journal of National Taipei Teachers College, Vol.17, No.1 (Mar. 2004) 571 584. NATIONAL TAIPEI TEACHERS COLLEGE 571

National Association for Sport and Physical Education (NASPE) Appropriate Practices In Movement Programs For Children Ages 3 - 5. AAHPERD Publications Fulfillment Center. United States

National Center for Chronic Disease Prevention and Health Promotion (NCCDPHP, 2000) early childhoood Longitudinal studi-Kindergarten class of 1998-1999, fall 1998, America's Kindergartners. Departemen of Education office of Education Research and Improment. USA

Thomas \& Nelson.(1996). Research Methods in Physical activity.Human Kinetic. USA.

Stephen A Butterfield, E Michael Loovis, Jaekyung Lee. (2008) Kicking Development by Children in Grades K-8: A Multi-Cohort Longitudinal Study. di download tangal 4 Maret 2012. Tersedia di:http://proquest. umi.com/pqdweb?index $=14 \&$ did $=2207301571 \&$ SrchMode $=1 \&$ Fmt $=3 \&$ 
VInst=ReferenceLinking \&VType $=P Q D \& R Q T=309 \&$ VName $=P Q D \& T$ $\mathrm{S}=1307939036 \&$ clientId $=83698$

Sherman, Nestor. (2002) Attitudes of preservice physical education majors regarding movement education. . Di downlad tanggal 1 maret 2012. Di http://search.proquest.com.ezproxy.ugm.ac.id/docview/215762839/1351 34305807BD1EF0B/2?accountid=13771

Seung-Hee Son, Samuel J Meisels. (2006) The Relationship of Young Children's Motor Skills to Later Reading and Math Achievement. di download tangal 4 Maret 2012. Tersedia di: http://proquest.umi.com /pqdweb?index $=30 \&$ did $=1223531261 \&$ SrchMode $=1 \&$ sid $=7 \&$ Fmt $=3 \&$ VInst=PROD\&VType $=$ PQD \&RQT $=309 \& V$ Name $=P Q D \& T S=1306830$ $674 \&$ clientId $=83698$

Sukadiyanto. (2010). Pengantar teori dan metodologi melatih fisik. Yogyakarta: FIK Universitas Negeri Yogyakarta.

Widiastuti. (2011). Tes dan pengukuran olahraga. Jakarta: PT Bumi Timur Jaya 